УДК 37.022

DOI: 10.23951/1609-624X-2020-1-94-103

\title{
УЧЕБНАЯ ЗАДАЧА В ЦИФРОВОЙ СРЕДЕ ЛИЧНОСТНО ОРИЕНТИРОВАННОГО ОБУЧЕНИЯ*
}

\author{
T. Н. Носкова, Т. Б. Павлова
}

Российский государственный педагогический университет им. А. И. Гериена, Санкт-Петербург

\begin{abstract}
Введение. На основе целей и задач обновления содержания и методов современного образования обосновывается актуальность раскрытия потенциала цифровой среды для реализации личностно ориентированного обучения, поиска эффективных приемов педагогического сопровождения индивидуализированной самостоятельной работы обучающегося в новых информационных условиях.

Материалы и методы. Предложена и методологически обоснована реализация задачного подхода к организации самостоятельной работы обучающихся в цифровой среде. В качестве обязательного условия рассматривается «культуросообразность» этого подхода, т. е. соответствие уровню современной информационной культуры и востребованных обществом образовательных результатов. Определены ключевые черты учебной задачи в цифровом пространстве в плане целеполагания, оперирования содержанием, освоения цифровых инструментов, взаимодействия с другими субъектами, учета индивидуальных потребностей и запросов обучающихся, проявляющихся в их информационном поведении. Введено и раскрыто понятие «цифровая микросреда учебной задачи», воплощающее специфику постановки учебных задач и формирования ситуаций их решения в цифровом образовательном пространстве.

Результаты и обсуждение. Приведены и проанализированы результаты опросов студентов и преподавателей университета, позволившие выявить реальные черты педагогической деятельности в цифровом образовательном пространстве и соотнести их с отношением студентов к использованию различных приемов взаимодействия с ресурсами и субъектами цифровой образовательной среды. Данные подтвердили, что большая часть преподавателей не в полной мере реализует потенциал цифровой образовательной среды в контексте приоритетов современного образования и в недостаточной степени ориентируется на информационные и коммуникационные запросы студентов.

Заключение. Учебная задача рассматривается как единица, в соответствии с которой в цифровой среде организуется самостоятельная учебно-познавательная деятельность. Проектирование цифровых микросред решения учебных задач позволяет в широком диапазоне реализовать возможности организации продуктивной личностно ориентированной самостоятельной работы обучающихся. Характер учебной деятельности в цифровой микросреде зависит как от педагогической методологии, так и от образовательной позиции и особенностей информационного поведения обучающегося.
\end{abstract}

Ключевые слова: ицировая образовательная среда, личностно ориентированное обучение, учебная задача, самостоятельная работа.

\section{Введение}

Пристальное внимание педагогического сообщества к идеям личностно ориентированного обучения («student-centred learning» или «learner first») и изучению условий его реализации в современной образовательной среде обусловлено как современными образовательными стандартами, так и перспективами трансформации запросов рынка труда (навыки будущего, новые модели компетенций). В сложном и быстро меняющемся мире в образовании особую роль приобретает всесторонняя поддержка становления человека как полноценного автора своей жизни, расширение спектра образовательных результатов [1-3]. В этом контексте важную роль играет самостоятельная работа обучающегося, в особенности ее внеаудиторная часть, которая обеспечивает формирование и проявление на практике целевых компетенций, позволяет развивать навыки самоорганизации, самообразования, непрерывного личностного и профессионального развития.

В формулировке И. С. Якиманской особенности педагогической деятельности в «личностно ориентированной школе» заключаются в координации усилий учащихся, предоставлении им выбора действия (учебного, поведенческого), формировании умений контролировать и оценивать свои действия, умений уважать мнение других и аргументированно отстаивать собственную точку зрения» [4]. В. В. Сериков связывает концепцию личностно ориентированного обучения с раскрытием условий личностно-развивающих функций: мотивации, рефлексии, смыслотворчества, самореализации и т. п. [5]. A. Semple (Semple, 2000) следующим образом обозначает основополагающие принципы личностно ориентированного обучения: приоритет

\footnotetext{
* Работа выполнена за счет гранта Российского научного фонда (проект № 19-18-00108 «Цифровизация профессиональной подготовки в высшей школе в контексте форсайта образования 2035»).
} 
личного опыта обучающегося и самостоятельно освоенных знаний; обучение как личная интерпретация мира; обучение как активный процесс создания смысла из опыта; обучение в контексте, относящемся к учащемуся; обучение - совместный процесс [6].

Вопросы педагогического сопровождения, обеспечения информационных и деятельностных условий внеаудиторной самостоятельной работы обучающихся обсуждаются в многочисленных публикациях, в которых раскрываются различные подходы к решению данной проблемы [7-9]. Практически все авторы подчеркивают необходимость использования возможностей цифровой образовательной среды для подготовки обучающихся действовать в меняющейся, подвижной знаниевой и технологической ситуации, самостоятельно воспринимать и осваивать новое и перспективное в учебной и предстоящей профессиональной деятельности. При этом проблемой является организация личностно эффективной образовательной активности в цифровом окружении.

\section{Материалы и методы}

Задачный подход в организачии самостоятельной работы обучающихся в ичирровой среде.

И. Я. Лернер, один из разработчиков задачнодеятельностного подхода в дидактике, рассматривал в качестве предмета обучения то, что можно представить как деятельность по решению учебной задачи, деятельность по освоению специально отобранных видов культурного опыта в единстве содержательного и процессуального. Он утверждал, что «если мы хотим, чтобы деятельность носила личностно-развивающий характер, то учебные задачи и создаваемые с их помощью учебные ситуации должны существенно отличаться от традиционных когнитивно-ориентированных». Также автор подчеркивал, что «поскольку пространство культурного опыта человечества постоянно расширяется и преобразуется, то и содержание образования обречено на непрерывное обновление, что и составляет приоритетный предмет дидактического исследования» [10]. В цифровой образовательной среде должны динамично отражаться новые черты современной информационной культуры человека, новые пути формирования образовательного, профессионального, социального опыта.

Задачный подход к деятельностному освоению содержания образования развивали Г. А. Балл, В. В. Давыдов, И. А. Зимняя, Д. Б. Эльконин и др., рассматривая учебную задачу не как единицу осваиваемого содержания, а как единицу учебной деятельности, вносящей вклад в формирование необходимых знаний, умений, компетенций обучающихся. Этот подход предоставляет возможность учесть специфику учебной активности в цифровой среде и показать новые возможности организации деятельности субъекта по решению учебно-познавательных задач с учетом разнообразной функциональности цифровых инструментов, ресурсов и сетевых форм взаимодействия. Учебные задачи должны найти новую цифровую реализацию, максимально отражать перспективные образовательные, культурные и профессиональные тренды, раскрывать разнообразные возможности деятельности по решению задачи для каждого обучающегося.

Традиционно учебная задача представлялась в виде текста с отсылкой к рекомендуемым информационным ресурсам. В одной из трактовок учебная задача имеет следующую структуру: общая формулировка, ключевое задание, в котором обозначен практический результат и форма его выражения, контекст решения, рекомендуемые действия по решению задачи, подсказки и помощь, задания по выбору [11].

В цифровом пространстве все структурные компоненты учебной задачи могут трансформироваться по форме и характеру учебных действий с возможностью получения обогащенного личностного образовательного результата. Активность субъекта в цифровой среде базируется на том, что современная компьютерная техника, мобильные гаджеты, сетевые технологии изначально предназначены для расширения функциональности индивидуальных действий человека, формирования индивидуальной траектории его информационной деятельности [12], т. е. все большего согласования действий человека со спецификой его индивидуальных особенностей, потребностей и запросов. Важно учесть в образовательном взаимодействии вариативность информационного поведения молодых людей (поколения next), которые привычно ориентируются в открытых информационных пространствах, применяют разнообразные цифровые инструменты, стремятся к мобильности и многозадачности. Если в цифровом образовательном пространстве не предусмотрены достаточные условия для изменения характера учебной деятельности, то обучающийся получает лишь более удобный доступ к учебным материалам и фактически не ориентирован на обогащенный индивидуализированный результат решения задач.

Для решения учебной задачи в цифровой среде должен быть подготовлен особый комплекс личностно ориентированных условий с учетом актуальных содержательных, технологических, социальных контекстов. Если в качестве образовательного результата рассматривать обогащенный комплекс умений, а в качестве приоритета личностную ориентированность учебных действий, то большинство традиционных учебных задач не могут 
быть без изменений «оцифрованы» и перенесены в новые информационные условия.

Очевидно, в первую очередь необходимо обеспечивать «цифровое оснащение» тех типов задач, которые недостаточно эффективно решаются традиционными способами или вообще не решаются без привлечения современных цифровых средств. В содержательном аспекте это задачи, позволяющие осваивать новейшие знания и технологические достижения, задействовать опыт профессионального сообщества, приобретать «цифровые навыки». В деятельностном аспекте важен процесс решения задачи обучающимся с возможностью выявлять личностные смыслы, актуализировать для себя цели, находить оптимальные способы действий и средства достижения результата (цифровое расширение личностно ориентированных возможностей решения задачи).

В учебной деятельности, как и любой другой, выделяют внешний и внутренний планы (Л. С. Выготский, А. Н. Леонтьев, П. Я. Гальперин и др.). Элементами внешней структуры учебной деятельности являются предлагаемые учебные задачи и ситуации их решения, рекомендуемые учебные действия и контроль их осуществления, оценка результата обучения.

Внешняя структура учебной деятельности может быть существенно изменена благодаря инновационным качествам цифровой образовательной среды. Эти изменения анализируются в информационном, коммуникационном и регуляционном аспектах взаимодействия ее субъектов [13].

С точки зрения взаимодействия с образовательной информацией в процессе решения учебной задачи в цифровой среде обучающийся получает возможность действовать в ситуациях избыточности, мультимедийной привлекательности, неоднозначности источников знаний, использовать интерактивность образовательных ресурсов, применять разнообразные программные средства для продуктивной обработки информации и пр. Соответственно, расширяется как содержательная основа учебных задач, так и инструментальность их постановки, предъявления и решения.

Учебно-познавательная задача, обогащенная разнообразными моделями сетевого взаимодействия субъектов, становится не только более гибкой по отношению к деятельностным потребностям и предпочтениям обучающегося, но также вносит вклад в становление перспективных образовательных, социальных и профессиональных компетенций (навыки распределенной деятельности, ощущение причастности к образовательному и профессиональному сообществу).

Контроль и оценивание решения учебной задачи в цифровой среде трансформируются в ком- плекс особых условий для саморегуляции и самоуправления учебными действиями, с существенным расширением диапазона возможностей, предоставляемых обучающемуся для осознанного целеполагания, планирования, самооценивания учебных действий и результатов. Это меняет и обогащает учебный образовательный опыт обучающегося, актуализирует личностные смыслы и рефлексию в процессе решения задач.

По мнению Л. С. Выготского внешняя структура деятельности влияет на внутренний план деятельности. При этом влияние оказывают два важных взаимосвязанных момента внешнего плана деятельности: «это орудийная (“инструментальная”) структура деятельности человека и ее включенность в систему взаимоотношений с другими людьми» [14]. Сегодня разнообразные цифровые инструменты, применяемые в том числе и для взаимодействия в сетевом пространстве, позиционируются как новые орудия труда. Включение их в решение учебных задач, использование актуальных знаковых систем позволяет организовать для субъекта «культуросообразную» практическую активность, отражающую современный этап взаимодействий в обществе и способствующую формированию соответствующего внутреннего плана учебной деятельности.

Поскольку обогащенный индивидуализированный образовательный результат рассматривается в единстве внешнего и внутреннего планов учебной деятельности, в постановке и решении учебно-познавательной задачи (как единицы организации самостоятельной учебно-познавательной деятельности субъекта) необходимо в полной мере задействовать потенциал цифровой среды. Это позволит обогатить все компоненты деятельности (цели, средства, действия и результаты), создавая условия личностно ориентированного обучения (возможности для поиска собственных смыслов, усиления мотиваций, формирования собственной позиции).

Специфика постановки учебных задач в ичифровой образовательной среде.

Основываясь на общей теории учебных задач (Г. А. Балл, Е. И. Машбиц и др.), рассмотрим особенности постановки и процесса решения учебной задачи в цифровой образовательной среде. Г. А. Балл подчеркивал необходимость изначально учитывать в задаче разнообразие образовательных возможностей и потребностей обучающихся, поскольку «способ решения задачи всегда соотносится с субъектными характеристиками человека-решателя, которые определяют не только выбор и последовательность операций, но и общую стратегию решения» [15].

Обозначенные выше особые качества цифровой среды, с одной стороны, должны способствовать 
тому, чтобы задача была лучше понята и принята обучающимся во всех ее частях: целеполагающей, содержательной и критериальной. С другой стороны, проявляются возможности для постановки новых учебных задач, ярко отражающих специфику перспективных образовательных результатов и современных трендов подготовки к цифровизации профессиональной деятельности.

Целеполагающая часть учебной задачи способствует мотивации, принятию и уточнению целей обучающимся. Мультимедийные мотивирующие блоки, наглядная демонстрация проекта результатов, практических примеров, вариантов решения задачи способствуют вовлечению обучающегося в индивидуализированный процесс целеполагания, эмоционального восприятия задачи, акцентированию передовых цифровых инструментальных и социальных компетенций (расширение спектра целей решаемой задачи). Цели решения задачи важно задавать как проект вариативных действий в расширенной цифровой среде, приводящих планируемому результату. Особая постановка учебной задачи в цифровом формате позволяет учесть в этом проекте различные мотивы и интересы обучающихся, предложить варианты действий и взаимодействия, способствующие проявлению образовательной инициативы, нацелить на поиск новых знаний.

Содержательная часть задачи также может быть представлена в различных цифровых форматах и предполагать возможность выбора формы представления содержания в соответствии с предпочтениями обучающегося. Условие задачи может включать не только описание вопроса, проблемы, но и ее реалистическую или смоделированную демонстрацию, а также цифровые инструменты, которые позволяют эту проблему увидеть и исследовать самостоятельно. Также в содержательную часть задачи обычно входят рекомендации по ее решению. В цифровом воплощении задачи такие рекомендации могут быть представлены в виде гипертекста, инфографики, анимации, скринкаста, контекстной помощи, интеллектуального агента и пр. Они ориентируют обучающегося на выбор средств решения задачи, определение предпочтений в плане индивидуальной или совместной деятельности, поддерживают инициативные учебные действия, в том числе с применением цифровых инструментов. Все это позволяет субъекту использовать в процессе решения задачи расширенную информационную и коммуникационную базу цифровой среды, соотнести обогащенные информационные условия решения задачи с содержанием формируемых навыков, компетенций.

Критериальная или оценочная часть учебной задачи в цифровом воплощении существенно ме- няется за счет предоставления обучающемуся возможностей рефлексивного управления учебными действиями. При постановке задачи учитывается, что не только результат решения задачи, но также процесс его достижения является предметом оценивания (реализуемого с использованием автоматизированных и интеллектуальных инструментов, во взаимодействии с членами образовательного сообщества и пр.), что позволяет поддерживать оперативную обратную связь для корректировки учебных действий или осознания обучающимся их эффективности и успешности [16].

Поэтому необходимо отметить, что постановка учебных задач в цифровой среде предполагает:

- расширение спектра образовательных целей и возможностей их осмысления;

- ориентировку на получение обогащенного результата решения учебной задачи как в содержательном, так и в личностном аспектах;

- отражение актуальных содержательных, социальных, технологических, инструментальных изменений в осваиваемой области;

- предоставление обучающемуся дополнительных оснований и возможностей для выбора путей и инструментальных средств решения задачи.

Ситуации решения учебных задач в ичифровой среде.

Вариативные ситуации решения учебной задачи призваны обеспечить выбор обучающимся, решающим задачу, способа достижения принятых целей, поддержать личностно-эффективный характер учебных действий. По мнению В. В. Давыдова, постановка учебной задачи должна ввести учащегося в ситуацию, требующую ориентации на содержательно общий способ ее решения во всех возможных частных и конкретных условиях [17]. В цифровой среде учебные ситуации могут варьироваться в трех аспектах:

- информационном (способ представления задачи и информационный инструментарий ее решения);

- коммуникационном (реализация помощи субъекту в процессе решения задачи, которая осуществляется через коммуникацию с педагогом, другими обучающимися или интерактивным ресурсом);

- управления действиями по решению задачи (организация контроля, оценивания, коррекции).

Вариативные ситуации решения учебной задачи не только обогащают и разнообразят учебную деятельность, но и позволяют трансформировать процесс решения учебной задачи в соответствии с расширенным спектром целей, позволяют учесть интересы, запросы, предпочтения обучающихся в деятельностном ключе, раскрывают дополнительные возможности для гибкого сочетания внешних и внутренних мотивов учебной деятельности, проявления индивидуального отношения к учению. 


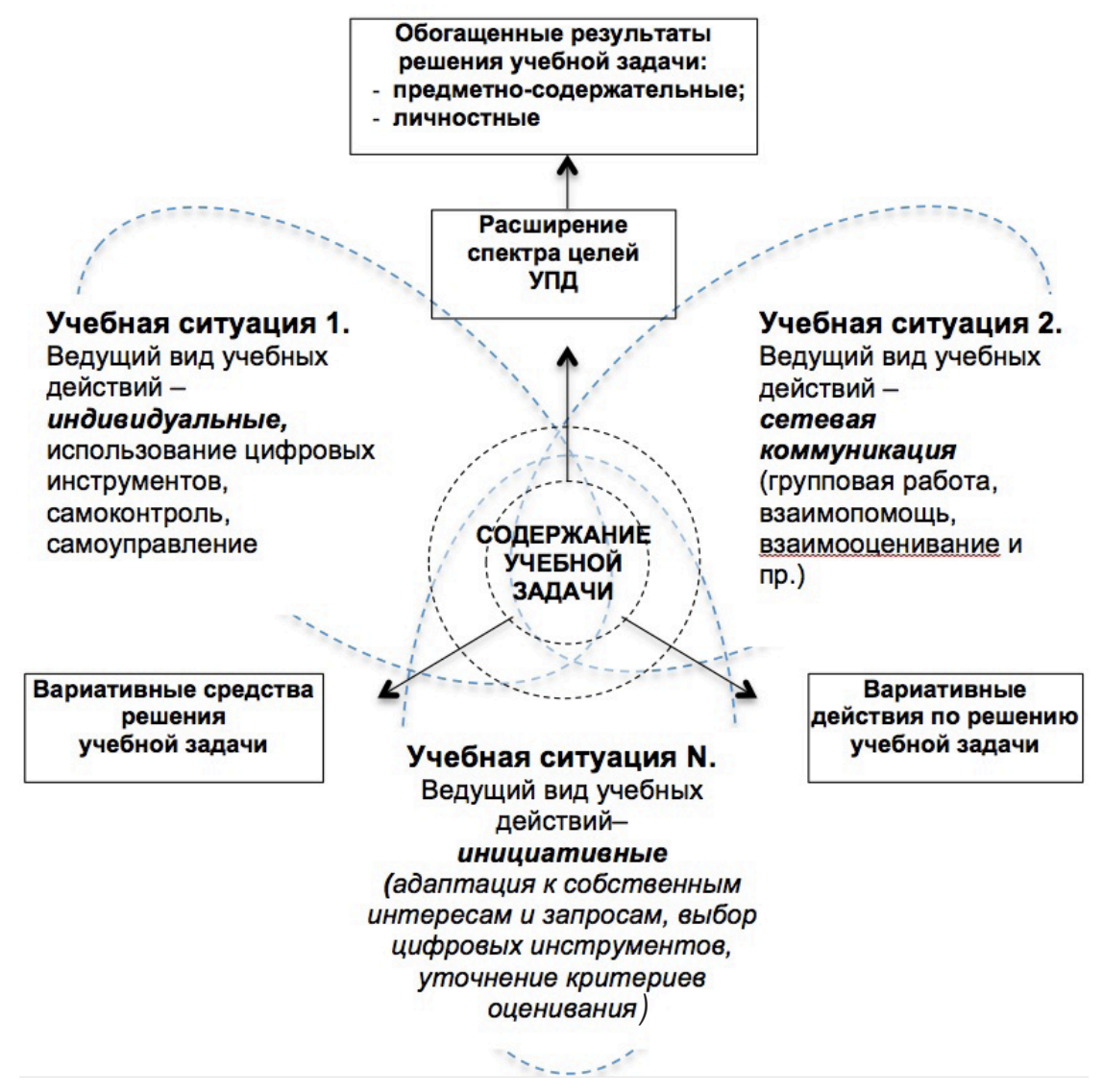

Рис. 1. Вариативные ситуации решения учебной задачи в цифровой среде

Ситуации решения учебной задачи с преобладанием индивидуальных учебных действий предполагают преимущественно работу обучающегося с необходимыми ресурсами в интерактивном режиме, получение консультаций и помощи по запросу. В регуляционном плане необходимо поддержать высокую степень самостоятельности и активности обучающегося в решении задачи.

Ситуации решения учебной задачи в совместной деятельности (партнерство, коллективная работа, взаимопомощь, взаимооценивание и пр.) используют в качестве ведущих учебных действий сетевую коммуникацию обучающихся. Такие ситуации требуют особого внимания к разработке коммуникационного пространства и педагогическому сопровождению взаимодействия субъектов учебной деятельности. Учебные ситуации такого рода вносят особый вклад в развитие перспективных социальных и профессиональных компетенций.

Благодаря высокому разнообразию ресурсов и инструментов цифровой образовательной среды обучающийся имеет возможность проявлять образовательную инициативу и фактически самостоятельно формировать ситуацию решения учебной задачи в соответствии с собственными предпочтениями, интересами и запросами в информационном, коммуникационном и регуляционном планах.
Это существенный фактор в становлении открытой познавательной позиции обучающегося, приобретении способности самостоятельно строить образовательный путь (рис. 1).

Цифровая микросреда учебной задачи.

Таким образом, педагог должен научиться формировать особое цифровое окружение обучающегося для решения учебных задач, реализовывать в нем вариативные учебные ситуации. Обозначим его как «цифровая микросреда решения учебной задачи».

Цифровая микросреда решения учебной задачи представляет собой комплексный цифровой образовательный ресурс, характеризующийся избыточностью (возможностью выбора, расширения):

- информационных источников, используемых при постановке и решении задачи;

- способов и целей взаимодействия субъектов, участвующих в решении задачи, цифровых инструментов решения задачи;

- способов и средств оценивания и опосредованного управления деятельностью по решению задачи.

Цифровая микросреда учебной задачи строится на базе научных концептов психодидактики электронной образовательной среды (информация, коммуникация, управление учебно-познавательной 
Носкова Т. Н., Павлова Т. Б. Учебная задача в иифровой среде...

деятельностью) [13], которые должны трансформироваться в связке на базе компьютерных средств для достижения обогащенного образовательного результата. Основу микросреды составляют цифровые ресурсы трех видов: ресурсы, обеспечивающие самостоятельное взаимодействие с осваиваемым содержанием; ресурсы, обеспечивающие образовательную коммуникацию в процессе решения задачи; ресурсы, задающие регуляционные действия в процессе решения задачи [18]. Назначением этих ресурсов является не только активное самостоятельное включение субъектов в процесс решения задачи, но также «погружение» в ситуации, демонстрирующие современные пути овладения знаниями, приобретение навыков использования разнообразных цифровых инструментов, продуктивных форм взаимодействия в целенаправленной практической деятельности.

Ключевым качеством такой цифровой микросреды является открытость, подразумевающая вариативность учебных действий на основе свободного или направляемого выбора обучающегося, возможность гибкой и оперативной модификации комплекса условий со стороны педагога или обучающихся, проявляющих образовательную инициативу. Многомерный выбор, включающий как содержание, так и учебные действия в цифровом пространстве, является новым дидактическим условием повышения качества решения учебных задач. Он вносит существенный вклад в развитие обучающегося как активного субъекта, стремящегося самостоятельно приобрести актуальные знания и умения, востребованные социальные навыки и качества личности, освоить перспективные формы образовательного и профессионального поведения.

\section{Результаты и обсуждение}

О востребованности обучающимися «цифрового разнообразия учебного окружения» свидетельствуют данные, полученные в результате опроса студентов 1-го курса на заключительном этапе освоения дисциплины «Информационные технологии». Студенты уже сформировали развернутое представление о многообразных возможностях цифровой образовательной среды, приобрели умения применять отдельные цифровые инструменты. При анализе результатов опроса делалась поправка на возможно завышенную самооценку, что связано с тем, что студенты анализировали умения и отношение к использованию различных цифровых инструментов лишь в приложении к решению задач конкретной дисциплины, а не к систематической информационной образовательной активности в цифровой среде.

Видим, что печатные учебные издания не занимают лидирующую позицию среди источников образовательной информации; обучающиеся видят разнообразные цифровые альтернативы. Но в то же время настораживает, что почти $42 \%$ студентов показали, что довольно часто используют информацию из недостоверных источников. Студенты явно отдают предпочтение образовательному видеоконтенту, интерактивные образовательные ресурсы востребованы практически наравне с традиционными учебными текстами, что говорит о необходимости учитывать разнообразные запросы во взаимодействии с образовательной информацией в построении цифровых микросред решения учебных задач.

Данные, приведенные в табл. 1, 2, показывают, что студенты проявляют заинтересованность в применении разнообразных приемов, позволяющих активно взаимодействовать с цифровой образовательной информацией, перерабатывать содержание, получая индивидуализированный информационный продукт. Но они также стремятся использовать традиционные способы взаимодействия с образовательными ресурсами. Ярко выражены предпочтения в отношении игровых приемов. Распределение ответов по остальным предложенным вариантам примерно одинаковое, но также свиде-

Разнообразие источников образовательной информации в учебном процессе

Таблица 1 (предпочтения студентов по 5-балльной шкале)

\begin{tabular}{|c|c|c|c|c|c|}
\hline $\begin{array}{c}\text { Оценка предпочтений студентов, \% } \\
\text { Источники информации }\end{array}$ & 1 & 2 & 3 & 4 & 5 \\
\hline Официальные сайты научных, образовательных организаций & 2 & 4 & 15 & 37 & 42 \\
\hline Авторитетные СМИ & 3 & 10 & 30 & 27 & 30 \\
\hline Электронные библиотеки образовательного назначения & 3 & 7 & 20 & 31 & 39 \\
\hline Информационные порталы и базы данных & 1 & 9 & 20 & 33 & 37 \\
\hline Личные сайты авторитетных специалистов и ученых & 6 & 13 & 14 & 38 & 29 \\
\hline Сайты, принадлежность которых не ясна & 27 & 23 & 8 & 23 & 19 \\
\hline Образовательные видеоканалы и подкасты & 6 & 6 & 21 & 23 & 44 \\
\hline Печатные учебные издания & 14 & 20 & 19 & 32 & 15 \\
\hline Открытые электронные библиотеки & 2 & 6 & 11 & 27 & 54 \\
\hline Файлообменники и торрент-трекеры & 18 & 14 & 22 & 21 & 25 \\
\hline
\end{tabular}


Разнообразие интерактивных приемов взаимодействия с образовательной информачией (предпочтения студентов по 5-балльной шкале)

\begin{tabular}{|c|c|c|c|c|c|}
\hline $\begin{array}{c}\text { Оценка предпочтений студентов (\%) } \\
\text { Интерактивные приемы взаимодействия } \\
\text { с образовательной информацией }\end{array}$ & 1 & 2 & 3 & 4 & 5 \\
\hline \multicolumn{6}{|c|}{ Приемы, способствующие усвоению материала } \\
\hline Добавление комментариев и заметок & 22 & 9 & 21 & 18 & 30 \\
\hline Автоматизированное тестирование для тренировки и самоконтроля & 4 & 10 & 10 & 42 & 34 \\
\hline $\begin{array}{l}\text { Приложения для работы с флеш-карточками (приложения типа Quizlet, } \\
\text { Flashcard Exchange, BrainFlips) }\end{array}$ & 10 & 7 & 20 & 25 & 38 \\
\hline Интерактивные таймлайны (сервисы и приложения типа Timegraphics) & 14 & 14 & 16 & 30 & 26 \\
\hline $\begin{array}{l}\text { Генерация облака ключевых слов текста (сервисы типа Облакослов, Tagxedo } \\
\text { и др.) }\end{array}$ & 14 & 14 & 16 & 28 & 28 \\
\hline Традиционные приемы взаимодействия с текстом & 13 & 8 & 17 & 33 & 29 \\
\hline \multicolumn{6}{|c|}{ Приемы, способствующие проверке понимания освоенного содержания } \\
\hline Мобильные опросы & 6 & 7 & 19 & 26 & 42 \\
\hline Тесты для контроля и самоконтроля & 4 & 5 & 16 & 35 & 40 \\
\hline Составление схем, интеллектуальных карт (перекодирование информации) & 10 & 5 & 21 & 21 & 43 \\
\hline Ответы на контрольные вопросы & 6 & 5 & 22 & 38 & 29 \\
\hline Заполнение таблиц (концептуальных, сравнительных и пр.) & 3 & 9 & 17 & 38 & 33 \\
\hline $\begin{array}{l}\text { Интерактивные задания на составление и сопоставление рядов, кроссвордов } \\
\text { (сервисы типа Learning Apps) }\end{array}$ & 8 & 13 & 16 & 29 & 34 \\
\hline Интерактивные обучающие игры & 5 & 5 & 9 & 19 & 62 \\
\hline \multicolumn{6}{|c|}{ Приемы, способствующие применению знаний } \\
\hline Составление тестов, кроссвордов, викторин, игр & 5 & 10 & 15 & 34 & 36 \\
\hline $\begin{array}{l}\text { Обсуждение с другими обучающимися (форум, дискуссия в соц. сети, } \\
\text { ведение блога) }\end{array}$ & 2 & 4 & 15 & 40 & 39 \\
\hline Взаимооценивание (вики, сетевые документы и пр.) & 8 & 9 & 22 & 30 & 31 \\
\hline $\begin{array}{l}\text { Скрайбинг (объяснение, взаимообучение через эскизы, рисунки, сервисы } \\
\text { типа Sparkol ) }\end{array}$ & 11 & 7 & 21 & 33 & 28 \\
\hline Сторителлинг (сервисы и приложения инфографики, анимации, видео) & 4 & 6 & 21 & 44 & 25 \\
\hline Традиционные приемы & 4 & 8 & 23 & 38 & 27 \\
\hline
\end{tabular}

тельствует о желании студентов учиться в интерактивном режиме. В таблицы не включены данные, показывающие, что более 70 \% студентов высоко оценили возможности использовать в учебном процессе материалы МООС.

Таким образом, студенты демонстрируют достаточно высокую готовность использовать и осваивать разнообразные цифровые способы решения учебных задач, что можно рассматривать как реальные предпосылки для существенного преобразования характера учебных действий в цифровой среде. Поскольку картина цифровых учебных предпочтений неоднородна и подвижна, вариативны по своим функциям и возможностям должны быть условия и ситуации решения учебных задач.

Но потенциал цифровой среды далеко не всегда задействован в образовательном взаимодействии в полной мере. В педагогической практике часто проявляется противоречие между доступностью цифровых средств, особых методических приемов на базе информационных и коммуникационных технологий и невысокой степенью их интегрированности в организацию самостоятельной работы обучающихся. Это подтверждают данные, полученные в результате анонимного опроса препода- вателей, достаточно активно применяющих информационные технологии в профессиональной деятельности (80 респондентов). Участникам опроса было предложено выбрать позиции, наиболее точно отражающие реальные черты их педагогической деятельности; все вопросы были с множественным выбором ответов. Приведем обзор некоторых результатов.

Несмотря на то, что 57 \% преподавателей используют в своей работе электронные учебные курсы, 49 \% респондентов оценивают использование ИКТ инструментов в преподавании дисциплин как фрагментарное (в основном это презентация информации в аудитории, компьютерные тесты и электронная переписка). Среди целей, с которыми предоставляются обучающимся цифровые образовательные ресурсы, 77 \% преподавателей выбрали позицию «обеспечение доступности учебных материалов»; лишь 38 \% участников опроса выделили цель, связанную с индивидуализацией самостоятельной работы студентов. Подавляющее число преподавателей (80 \%) отметили, что набор образовательных ресурсов одинаков для всех студентов; 36 \% участников показали, что применяют в своей практике групповые и коллективные формы органи- 
зации самостоятельной работы студентов в цифровом пространстве; 25 \% указали на применение проектных форм деятельности; 18 \% включают в образовательное взаимодействие взаимооценивание образовательных результатов; 14 \% респондентов отметили, что учитывают в образовательном взаимодействии предложения и предпочтения студентов в отношении способов сетевой образовательной коммуникации.

Отметили цели повышения качества образования $51 \%$ опрошенных педагогов (в т. ч. формирование компетенций информационного общества и общества знаний); 43 \% участников опроса выбрали позицию, связанную с необходимостью исследования новых способов применения информационных инструментов для решения профессиональных задач; 31 \% ответов продемонстрировал желание преподавателей использовать современные модели информационного поведения, в т. ч. применяемые студентами.

Таким образом, видим, что основная проблема заключена не освоении цифровых инструментов решения учебных задач, а в несоответствии реальных педагогических позиций значительного числа преподавателей доступным возможностям и предназначению цифровой образовательной среды в контексте приоритетов современного образования.

\section{Заключение}

Рассматривая учебную задачу в качестве единицы организации самостоятельной учебно-познавательной деятельности субъекта в цифровой образовательной среде, противопоставляем задачный подход подходу структурно-содержательному, в соответствии с которым проектируется и разрабатывается значительное количество цифровых образовательных ресурсов и электронных учебных курсов. Проектирование разнообразных учебных ситуаций в «цифровых микросредах» решения учебных задач позволяет в широком диапазоне реализовать возможности организации продуктивной личностно ориентированной самостоятельной работы обучающихся, обеспечить пространство осознанного выбора образовательных действий в достижении расширенного спектра образовательных целей.

Цифровая микросреда учебной задачи может быть реализована в web-пространстве или в доступной LMS (системе управления обучением). Характер учебной деятельности в «микросреде» определяется как педагогической методологией, так и образовательной позицией и особенностями информационного поведения обучающегося.

\section{Список литературы}

1. Основные направления деятельности Правительства Российской Федерации на период до 2024 года. URL: http://government.ru/ news/34168/ (дата обращения: 16.06.2019).

2. Цели в области устойчивого развития до 2030 года. Качественное образование. URL: https://www.un.org/sustainabledevelopment/ru/ education/ (дата обращения: 16.06.2019).

3. Навыки будущего. Что нужно знать и уметь в новом сложном мире. URL: https://futuref.org/futureskills_ru (дата обращения: 16.06.2019).

4. Якиманская И. С. Личностно ориентированная школа: критерии и процедуры анализа и оценки ее деятельности // Директор школы. 2003. № 6. C. 27-36.

5. Сериков В. В. Развитие личности в образовательном процессе. М.: Логос, 2012. 447 с.

6. Semple A. Learning theories and their influence on the development and use of educational technologies // Australian Science Teachers Journal. 2000. Vol. 46 (3). P. 21-28.

7. Tekkol İlkay Aşkin, Melek Demirel. An Investigation of Self-Directed Learning Skills of Undergraduate Students // Frontiers in psychology. 2018. Vol. 9, № 2324. URL: https://www.frontiersin.org/articles/10.3389/fpsyg.2018.02324/full (дата обращения: 21.07.2019).

8. Остапенко А. В., Плехова Ю. О. Совершенствование организации самостоятельной работы студентов как путь повышения качества юридического образования // Педагогика. Вопросы теории и практики. 2018. № 4. С. 12-15.

9. Пак Ю. Н., Нугужинов Ж. С., Пак Д. Ю. Проблемы модернизации высшей школы в формате компетентностного подхода // Высшее образование сегодня. 2017. № 10. С. 48-52.

10. Сериков В.В.Дидактика Лернера: идеи и их развитие // Отечественная и зарубежная педагогика. 2017. № 3 (39). С. 19-30.

11. Компетентностный подход в педагогическом образовании / под ред. В. А. Козырева, Н. Ф. Радионовой. СПб.: Изд-во РГПУ им А. И. Герцена, 2004. 392 c.

12. Сергеева И. Л. Трансформация массовой культуры в цифровой среде // Культура и цивилизация. 2016. Т. 6, № 6А. С. 55-65.

13. Носкова Т. Н. Психодидактика информационно-образовательной среды: учебное пособие для студентов высших учебных заведений, обучающихся по направлениям педагогического образования. СПб.: Изд-во РГПУ им. А. И. Герцена, 2007. 171 с.

14. Леонтьев А. Н. Деятельность. Сознание. Личность: учеб. пособие. М.: Смысл, Академия, 2004. 352 с.

15. Балл Г. А. Теория учебных задач: Психолого-педагогический аспект. М.: Педагогика, 1990. 184 с.

16. Носкова Т. Н., Павлова Т. Б., Яковлева О. В. Инструменты педагогической деятельности в электронной среде // Высшее образование в России. 2017. № 8-9. С. 121-130.

17. Давыдов В. В. Теория развивающего обучения. М.: Интор, 1996. 544 с.

18. Сетевая образовательная среда, электронные ресурсы: учеб. пособие / под ред. Т. Н. Носковой. СПб.: Изд-во РГПУ им. А. И. Герцена, 2015. $114 \mathrm{c}$. 
Носкова Татьяна Николаевна, профессор, доктор педагогических наук, Российский государственный педагогический университет им. А. И. Герцена (Набережная реки Мойки, 48, Санкт-Петербург, Россия, 191186).

E-mail: noskovatn@gmail.com

Павлова Татьяна Борисовна, кандидат педагогических наук, доцент, Российский государственный педагогический университет им. А. И. Герцена (Набережная реки Мойки, 48, Санкт-Петербург, Россия, 191186).

E-mail: pavtatbor@gmail.com

Материал поступил в редакичию 23.09.2019.

\author{
DOI: 10.23951/1609-624X-2020-1-94-103
}

\title{
LEARNING TASK IN THE DIGITAL ENVIRONMENT OF PERSONALITY-ORIENTED EDUCATION
}

\section{T. N. Noskova, T. B. Pavlova}

Herzen State Pedagogical University of Russia, Saint Petersburg, Russian Federation

Introduction. Taking into account the updating goals and methods of modern education, the relevance of revealing the potential of the digital environment for the implementation of personality-oriented learning is justified. The search for effective methods of pedagogical support of an individualized student's work in new information conditions is substantiated.

Material and methods. The implementation of the objective approach to the organization of students' independent work in a digital environment is proposed and methodologically justified. As a prerequisite is considered the "culturecongruent" of this approach, i.e. compliance with the level of modern information culture and the educational results demanded by society. The key features of the learning task in the digital space are identified in terms of goal setting, content management, the development of digital tools, interaction with other subjects, taking into account the individual student's needs and requests, manifested in their information behavior.

The concept of "digital microenvironment of the learning task" is introduced and disclosed, embodying the specifics of setting educational tasks and creating situations for their solution in the digital education space.

Results and discussion. The results of surveys of university students and teachers are presented and analyzed, which made it possible to identify the real features of pedagogical activity in the digital education space and correlate them with the students' attitude to the use of various methods of interaction with resources and persons in the digital educational environment. The data confirmed that the majority of teachers do not fully realize the potential of the digital educational environment in the context of modern education priorities and are not sufficiently oriented to students' information and communication requests.

Conclusion. The learning task is considered as a unit, according to which an independent learning and cognitive activity is organized in the digital environment. The design of the "learning tasks of digital microenvironments" provides a wide range of opportunities for organizing a productive, personality-oriented independent student work. The nature of the educational activity in the "digital microenvironment" depends both on the pedagogical methodology and on the educational position and characteristics of the student's informational behavior.

Keywords: digital educational environment, personality-oriented learning, learning task, independent work.

\section{References}

1. Osnovnye napravleniya deyatel'nosti Pravitel'stva Rossiyskoy Federatsii na period do 2024 goda [The main activities of the Russian Federation Government for the period until 2024] (in Russian). URL: http://government.ru/news/34168/ (accessed 16 July 2019).

2. Tseli v oblasti ustoychivogo razvitiya do 2030 goda. Kachestvennoye obrazovaniye [Sustainable development goals until 2030. Quality education] (in Russian). URL: https://www.un.org/sustainabledevelopment/ru/education/ (accessed 16 July 2019).

3. Navyki budushchego. Chto nuzhno znat' i umet' $v$ novom slozhnom mire [Skills of the future. What you need to know and be able to in a new complex world] (in Russian). URL: http://spkurdyumov.ru/uploads/2017/10/navyki-budushhego-chto-nuzhno-znat-i-umet-v-novom-slozhnom-mire. pdf (accessed 16 July 2019).

4. Yakimanskaya I. S. Lichnostno oriyentirovannaya shkola: kriterii i protsedury analiza i otsenki eye deyatel'nosti [Personally oriented school: criteria and procedures for the analysis and evaluation of its activities]. Direktor shkoly, 2003, no. 6, pp. 27-36 (in Russian).

5. Serikov V. V. Razvitiye lichnosti v obrazovatel'nom protsesse [Personality development in the educational process]. Moscow, Logos Publ., 2012. 447 p. (in Russian).

6. Semple A. (2000). Learning theories and their influence on the development and use of educational technologies. Australian Science Teachers Journal, 2000, vol. 46 (3), pp. 21-28.

7. Tekkol İlkay Aşkin, Melek Demirel. An Investigation of Self-Directed Learning Skills of Undergraduate Students. Frontiers in psychology, 2018, vol. 9 2324. DOI: 10.3389/fpsyg.2018.02324. URL: https://www.frontiersin.org/articles/10.3389/fpsyg.2018.02324/full (accessed 16 July 2019) 
8. Ostapenko A. V., Plekhova Yu. O. Sovershenstvovaniye organizatsii samostoyatel'noy raboty studentov kak put' povysheniya kachestva yuridicheskogo obrazovaniya [Improving the organization of students' independent work as a way to improve the quality of legal education]. Pedagogika. Voprosy teorii i praktiki - Pedagogy. Issues of Theory and Practice, 2018, no. 4, pp. 12-15 (in Russian).

9. Pak Yu. N., Nuguzhinov Zh. S., Pak D. Yu. Problemy modernizatsii vysshey shkoly v formate kompetentnostnogo podkhoda [Problems of modernization of higher education in the format of competency-based approach]. Vyssheye obrazovaniye segodnya - Higher Education Today, 2017, no. 10, pp. 48-52 (in Russian).

10. Serikov V. V. Didaktika Lernera: idei i ikh razvitiye [Lerner didactics: ideas and their development]. Otechestvennaya i zarubezhnaya pedagogika, 2017, no. 3 (39), pp. 19-30 (in Russian).

11. Kompetentnostnyy podkhod v pedagogicheskom obrazovanii. Pod red. V. A. Kozyreva i N. F. Radionovoy [Competency-based approach in teacher education. Ed. V. A. Kozyreva and N. F. Radionova]. Saint Petersburg, Herzen State Pedagogical University of Russia Publ., 2004. 392 p. (in Russian).

12. Sergeeva I. L. Transformatsiya massovoy kul'tury $v$ tsifrovoy srede [The transformation of mass culture in the digital environment]. Kul'tura $i$ tsivilizatsiya - Culture and Civilization, 2016, vol. 6, no. 6A, pp. 55-65 (in Russian).

13. Noskova T. N. Psikhodidaktika informatsionno-obrazovatel'noy sredy: uchebnoye posobiye dlya studentov vysshikh uchebnykh zavedeniy, obuchayushchikhsya po napravleniyam pedagogicheskogo obrazovaniya [Psychodidactics of the information and educational environment: a textbook for students of higher educational institutions studying in the areas of teacher education]. Saint Petersburg, Herzen State Pedagogical University of Russia Publ., 2007. 171 p. (in Russian).

14. Leontiev A. N. Deyatel'nost'. Soznaniye. Lichnost': uchebnoye posobiye [Activity. Consciousness. Personality: study guide]. Moscow, Smysl, Akademiya Publ., 2004. 352 p. (in Russian).

15. Ball G. A. Teoriya uchebnykh zadach: Psikhologo-pedagogicheskiy aspekt [Theory of educational problems: Psychological and pedagogical aspect]. Moscow, Pedagogika Publ., 1990. 352 p. (in Russian).

16. Noskova T. N., Pavlova T. B., Yakovleva O. V. Instrumenty pedagogicheskoy deyatel'nosti v elektronnoy srede [Instruments of pedagogical activity in the electronic environment]. Vyssheye obrazovaniye v Rossii - Higher Education in Russia, 2017, no. 8-9, pp. 121-130 (in Russian).

17. Davydov V. V. Teoriya razvivayushchego obucheniya [Theory of Developmental Learning]. Moscow, Intor Publ., 1996. 544 p. (in Russian).

18. Setevaya obrazovatel'naya sreda, elektronnye resursy: uchebnoye posobiye. Pod red. T. N. Noskovoy [Network educational environment, electronic resources: a training manual. Ed. T. N. Noskova]. Saint Petersburg, Herzen State Pedagogical University of Russia Publ., 2015. 352 p. (in Russian).

Noskova T. N., Herzen State Pedagogical University of Russia (Naberezhnaya reki Moyki, 48, Saint Petersburg, Russian Federation, 191186). E-mail: noskovatn@gmail.com

Pavlova T. B., Herzen State Pedagogical University of Russia (Naberezhnaya reki Moyki, 48, Saint Petersburg, Russian Federation, 191186). E-mail: pavtatbor@gmail.com 